\title{
Serum Melanotransferrin, p97 as a Biochemical Marker of Alzheimer's Disease
}

\author{
Doh Kwan Kim, M.D., Ph.D., Min Young Seo, M.D., Shinn-Won Lim, M.S., Seonwoo Kim, M.D., \\ Jong-Won Kim, M.S., Bernard J. Carroll, M.D., Ph.D., Do Yoon Kwon, M.S., Taegun Kwon, M.S., \\ and Sang Sun Kang, Ph.D.
}

The protein melanotransferrin ( $p 97$ ) is associated with the brain lesions of Alzheimer's disease $(A D)$ and is a potential marker of the disorder. We measured serum $p 97$ concentrations in 211 subjects: 71 patients with $A D, 56$ patients with non-AD-type dementia, and 84 normal control subjects. Serum $p 97$ concentrations were elevated 3to 4-fold in $A D$ (median $15.00 \mathrm{pg} / \mu \mathrm{l}$, interquartile range $10.20-17.00 \mathrm{pg} / \mu \mathrm{l})$ as compared to non $A D$ dementia $(2.85$ $\mathrm{pg} / \mu \mathrm{l}, 1.93-7.15 \mathrm{pg} / \mathrm{\mu l})$ and normal controls $(3.20 \mathrm{pg} / \mu \mathrm{l}$, $2.55-3.95 \mathrm{pg} / \mu \mathrm{l})$. The mean elevation was significant at
$13.54 \pm 3.72 \mathrm{pg} / \mu \mathrm{l}$, even in the 38 subjects with mild $A D$ (CDR stage 0.5-1). Receiver operating characteristic analyses confirmed an optimal diagnostic threshold of 10.0 $\mathrm{pg} / \mu \mathrm{l}$, which yielded over-all accuracy of 0.882 to 0.915 . Serum $p 97$ is a candidate marker of $A D$, even in the early stage when clinical diagnosis is most uncertain.

[Neuropsychopharmacology 25:84-90, 2001] (C) 2001 American College of Neuropsychopharmacology. Published by Elsevier Science Inc.
KEY WORDS: Alzheimer's disease; Melanotransferrin; Biochemical marker

Alzheimer's disease (AD) is the most challenging of the clinical dementias, accounting for $70 \%$ of cases in most countries (Geldmacher and Whitehouse 1996). Early recognition of $\mathrm{AD}$ is important for a variety of clinical reasons, especially to initiate emerging treatments before neuronal loss occurs. However, the clinical diagno-

From the Departments of Neuropsychiatry (DKK, MYS) and Clinical Pathology (J-W K), Samsung Medical Center, Sungkyunkwan University School of Medicine; Samsung Biomedical Research Institute (S-W L, SK, TK), Seoul, Republic of Korea; Pacific Behavioral Research Foundation, Carmel, California, and Department of Psychiatry and Behavioral Sciences, Stanford University School of Medicine, Stanford, California, USA (BJC); and Department of Science Education, Chungbuk National University (DYK, SSK), Chongju, Republic of Korea.

Address correspondence to: Sang Sun Kang, Ph.D., Department of Science Education, Chungbuk National University, Chongju, 361763 Korea. Tel: +82-431-261-3278.

E-mail: 95324JIN@hitel.net

Received 21 March 2000; revised 18 October 2000; accepted 13 November 2000. sis is not always reliable, especially in mild AD (Nagy et al. 1999; Varma et al. 1999). A biochemical marker of AD would be a significant advance.

Candidate markers previously proposed include $\beta$-amyloid protein $(A \beta)$, tau protein, glutamine synthase, apoliproprotein E (ApoE), $\alpha_{1}$-antichymotrypsin, and chemokines. Another recently proposed marker is a novel molecule for iron uptake, melanotransferrin, also known as p97, that is expressed in capillary endothelium and in microglia associated with amyloid plaques in $\mathrm{AD}$ brain tissue (Jefferies et al. 1996a). The investigators who reported this pathological finding also conducted a limited clinical study of 17 patients with AD and 15 normal control subjects. They reported that the mean serum p97 concentration was elevated 6-fold in AD, with no overlap of the group distributions, and they suggested that p97 might be a marker of AD (Kennard et al. 1996). We have evaluated this suggestion in a more rigorous clinical study of 211 subjects: 71 patients with AD, 56 with non-AD-type dementias, and 84 normal subjects. The two clinical dementia groups were very similar in age and cognitive impairment (Table 1). 
Table 1. Characteristics of Subject Groups

\begin{tabular}{|c|c|c|c|c|c|c|c|c|c|}
\hline \multirow[b]{2}{*}{ Group } & \multirow[b]{2}{*}{ Number } & \multirow[b]{2}{*}{$\mathbf{F} / \mathbf{M}$} & \multirow[b]{2}{*}{ Age, $y$} & \multirow[b]{2}{*}{ Duration, m } & \multirow[b]{2}{*}{$\mathrm{CDR}^{a}$} & \multirow[b]{2}{*}{$\mathrm{K}-M M S E^{b}$} & \multicolumn{3}{|c|}{$\begin{array}{l}\text { ApoE alleles } \\
\text { frequency }\end{array}$} \\
\hline & & & & & & & $\epsilon 2$ & $\epsilon 3$ & $\epsilon 4$ \\
\hline Alzheimer-type dementia & 71 & $54 / 17$ & $70(62-75)$ & $28(18-48)$ & $1(1-2)$ & $14(10-21)$ & $2.8 \%$ & $66.2 \%$ & $31.0 \%$ \\
\hline Non-Alzheimer-type dementia & 56 & $35 / 21$ & $68(64-73.5)$ & $27(12-52)$ & $0.5(0.5-2)$ & $16(13-21)$ & $8.9 \%$ & $81.3 \%$ & $9.8 \%$ \\
\hline Vascular dementia & 41 & $26 / 15$ & $68(64-73)$ & $30(11-53)$ & $1(0.5-2)$ & $15(13-20)$ & $9.8 \%$ & $80.5 \%$ & $9.8 \%$ \\
\hline Parkinson's disease & 15 & $9 / 6$ & $69(63-74)$ & $22(12-52)$ & $0.5(0.5-1)$ & $18(15-23)$ & $6.7 \%$ & $83.3 \%$ & $10.0 \%$ \\
\hline Normal controls & 84 & $53 / 31$ & $32(29-60.5)$ & & & & $5.4 \%$ & $86.3 \%$ & $8.3 \%$ \\
\hline
\end{tabular}

Values of age, duration, CDR, and K-MMSE are reported as median and interquartile range.

${ }^{a} \mathrm{CDR}=$ clinical dementia rating.

${ }^{b} \mathrm{~K}-\mathrm{MMSE}=$ Korean version of mini-mental state examination.

${ }^{c}$ ApoE genotype $=$ apolipoprotein genotyping.

$\epsilon 2=2 \times \epsilon 2 / 2+\epsilon 2 / 3+\epsilon 2 / 4, \epsilon 3=2 \times \epsilon 3 / 3+\epsilon 3 / 2+\epsilon 3 / 4, \epsilon 4=2 \times \epsilon 4 / 4+\epsilon 4 / 3+\epsilon 4 / 2$

\section{METHODS}

\section{Subjects}

Patients were attending the Clinical Trials Program of the Samsung Medical Center Geropsychiatry Clinic. Standard diagnostic criteria were used for AD (McKhann et al. 1984), for vascular dementia (VD) (Roman et al. 1993), and for Parkinson's disease (PD) (Hughes et al. 1992). In our Geropsychiatry Clinic, the interobserver diagnostic reliability of $\mathrm{AD}$ and non-AD dementias is $90.3 \%$. Brain magnetic resonance imaging and electroencephalography were performed in all cases to exclude other possible causes of dementia. Patients with other neurologic or psychiatric disorders or clinically significant medical conditions were excluded. No patient had a history of head trauma, or alcohol or drug abuse. The study was approved by the Institutional Review Board. Written informed consent was obtained from all subjects, their spouses, or their legal guardians. All patients received a comprehensive neuropsychological screening battery, which cannot be detailed in this brief report. Severity of dementia was assessed with the Korean version of the Mini-Mental State Examination (K-MMSE) (Folstein et al. 1975) and the Clinical Dementia Rating (CDR) scale (Morris 1993). Duration of cognitive symptomatology was estimated. Normal subjects were healthy volunteers $(n=60)$ or spousal caregivers $(n=24)$ without cognitive impairment (K-MMSE score 26 or higher). Subjects provided a blood sample from which serum and DNA were prepared. Blood samples were stored at $4^{\circ} \mathrm{C}$ immediately after venipuncture and were assayed for $\mathrm{p} 97$ within $24 \mathrm{~h}$.

\section{Cell Culture}

SK-MEL 28 (a human melanoma cell line) and L235 (a hybrid cell line producing the melanoprotein mono- clonal antibody) were supplied by ATCC, Rockville, MD. Media and supplements were obtained from GIBCO, Grand Island, NY. These cell lines were grown into a $75 \mathrm{~cm}^{3}$ flask in Dulbecco's medium (DMEM) containing $10 \%$ heat-inactivated $\left(30 \mathrm{~min}\right.$. at $56^{\circ} \mathrm{C}$ ) fetal bovine serum, $100 \mathrm{mU}$ potassium penicillin $\mathrm{G} / \mathrm{ml}, 100 \mu \mathrm{g}$ streptomycin $/ \mathrm{ml}, 2 \mathrm{mM}$ glutamine, and $20 \mathrm{mM}$ sodium bicarbonate. The cells were incubated at 5\% $\mathrm{CO}_{2}, 95 \%$ humidity, and $37^{\circ} \mathrm{C}$ for 3 days.

\section{p97 Assay}

Each serum sample $(1 \mu \mathrm{l})$ and the standard p97 (isolated from SK-MEL 28 cell line) were spotted on a nitrocellulose membrane and dried completely. After soaking in the blocking solution for $1 \mathrm{~h}$ at room temperature, the membrane was incubated with p97 monoclonal antibody, L234 [ATCC-HB 8446 L235 (H19)] overnight at $4^{\circ} \mathrm{C}$. After washing three times in PBS (phosphate-buffered saline) containing $0.01 \%$ Tween 20 , the membrane was incubated with the secondary antibody conjugated with horseradish peroxidase for 1 $\mathrm{h}$ at room temperature. The membrane was washed three more times in PBS containing 0.01\% Tween 20, then incubated with the peroxidase substrate solution (LumiGLO, New England Biolabs, Inc.) for $1 \mathrm{~min}$ at room temperature. The membrane was exposed on X-ray film for $1 \mathrm{~min}$. The spot darkness on X-ray film was measured with the computer scanner, and the standard curve was constructed (pixel number vs. p97 standard concentration). Serum p97 concentrations were determined from a calibration curve prepared from the p97 standard as described by Kennard et al (1995). All values are reported as the average of triplicate determinations. Laboratory assays were performed blind to clinical diagnosis. The average coefficient of variation of the assay for p97 was $18.3 \%$. 


\section{ApoE Genotyping}

ApoE genotyping was determined by the method of Hixson and Vernier (1990).

\section{Statistical Analysis}

Medians and interquartile ranges of serum levels of p97, K-MMSE, duration of cognitive symptomatology, and age are presented as descriptive statistics. Nonparametric methods were applied to the statistical analyses of these variables, which were not normally distributed. The sex distributions of the groups were compared by Chi-square testing. For correlations between continuous variables, we used Spearman's rank correlation method. Serum p97 concentrations were adjusted for age by the analysis of covariance using ranks followed by the least significant difference test. Sensitivity, specificity, and accuracy were computed for the range of serum p97 concentrations, and receiver operating characteristic (ROC) curves were then constructed.
The optimal ROC solution was determined as the value with the least calculated distance from complete accuracy (Streiner and Norman 1995). SAS software (version 6.12) was used for statistical analyses.

\section{RESULTS}

\section{Distribution of Serum p97 in AD, Non-AD and Normal Subjects}

Serum p97 concentrations (Figure 1) were higher in AD (median $15.00 \mathrm{pg} / \mu \mathrm{l}$, interquartile range 10.20-17.00 $\mathrm{pg} / \mu \mathrm{l})$ than in non-AD dementia $(2.85 \mathrm{pg} / \mu \mathrm{l}, 1.93-7.15$ $\mathrm{pg} / \mu \mathrm{l})$ and normal subjects $(3.20 \mathrm{pg} / \mu \mathrm{l}, 2.55-3.95 \mathrm{pg} /$ $\mu \mathrm{l})$. The over-all group differences were significant $(p<$ .0001 by Kruskal-Wallis test). The over-all group differences remained significant after adjusting for age by analysis of covariance (ANCOVA) using ranks ( $p=$ .0001). Post-hoc testing revealed significant elevation of the serum p97 concentration in $\mathrm{AD}$ as compared to both

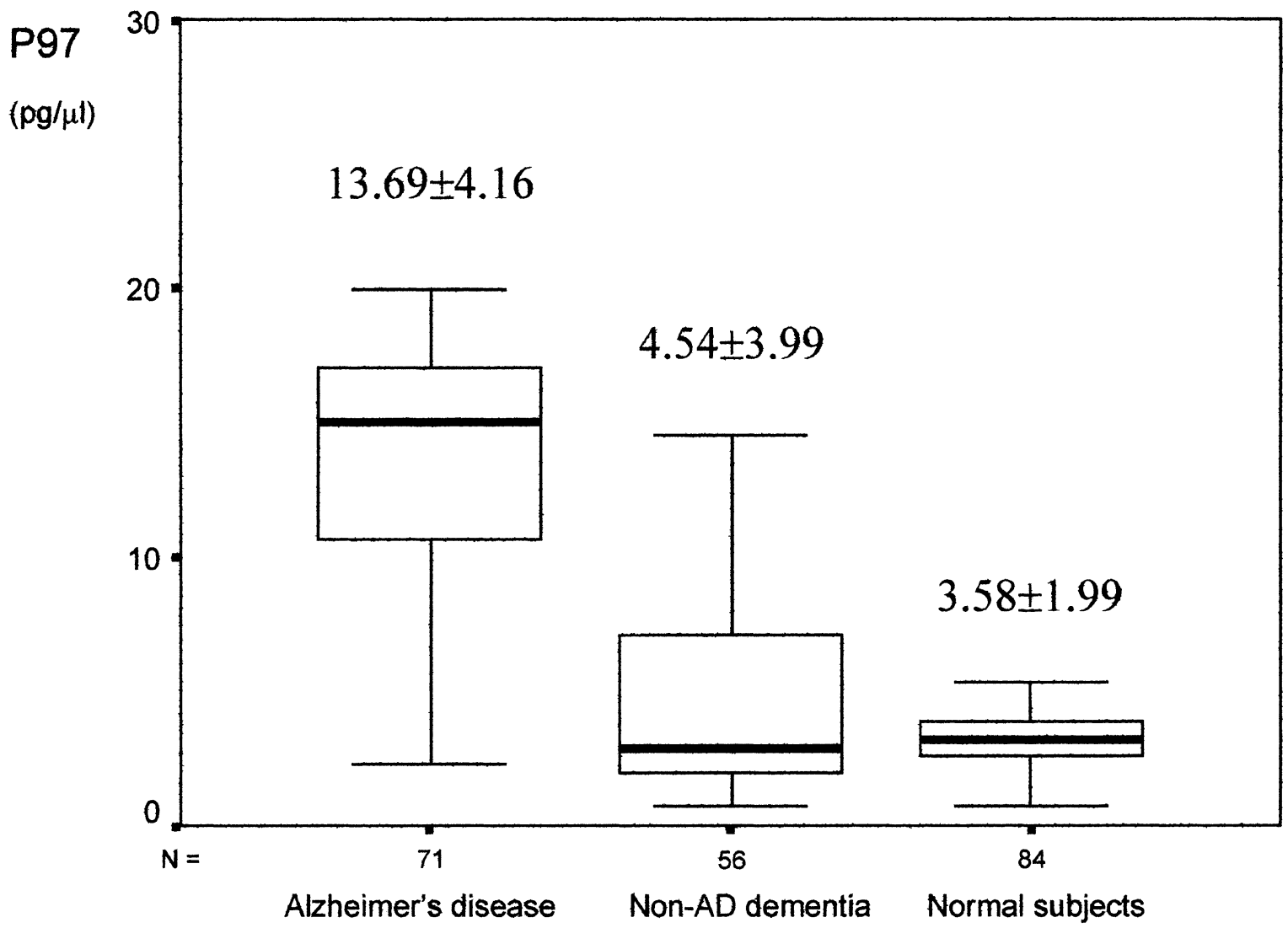

\section{Diagnostic Groups}

Figure 1. Boxplot comparison of serum p97 concentrations from patients with Alzheimer's disease (AD), non-Alzheimer type (non-AD) demented patients, and normal subjects. Each box displays the median, 75th percentile, and 25th percentile values; horizontal bars indicate the highest and lowest observed values. 


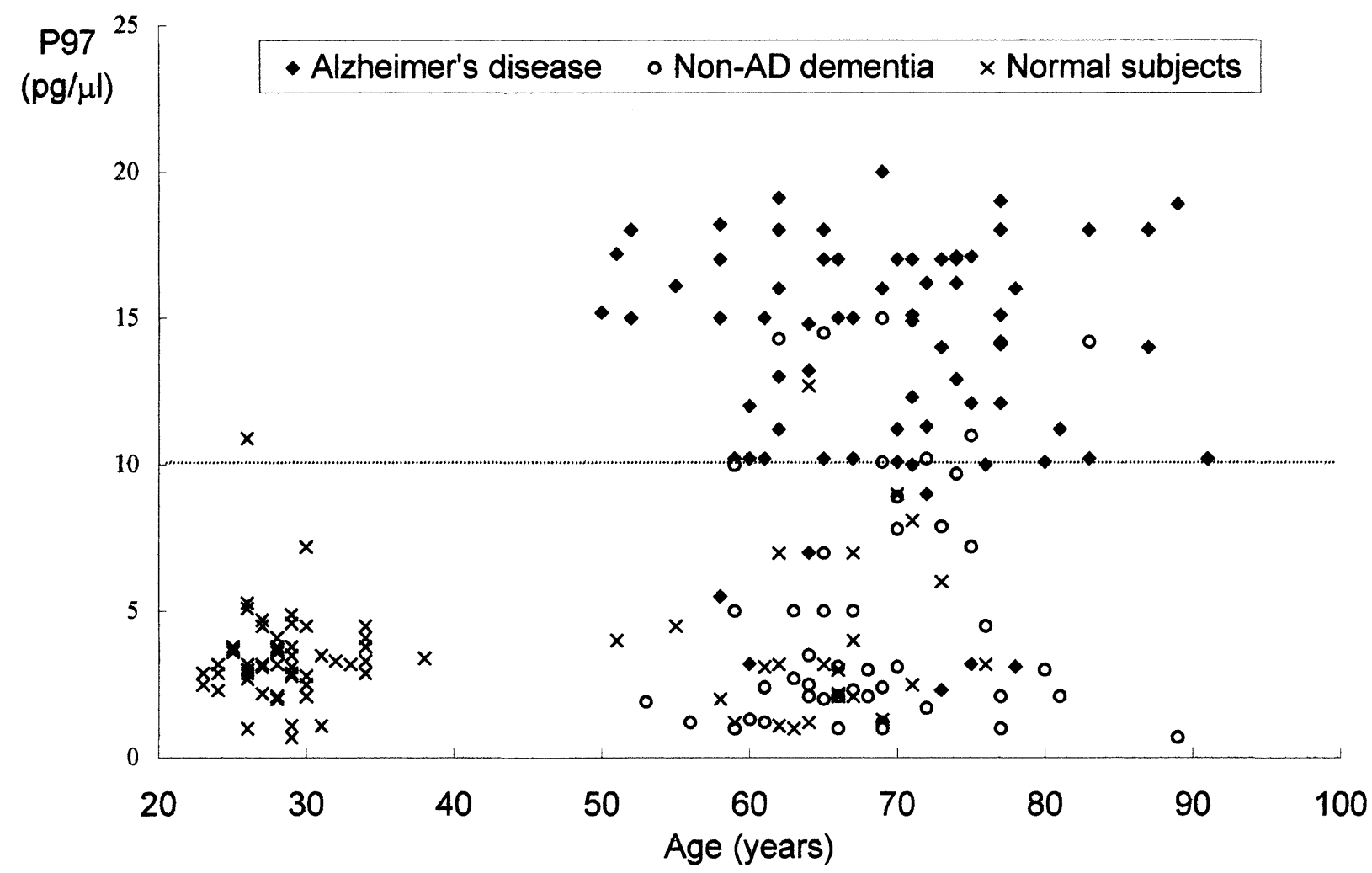

Figure 2. Scatter plot of p97 versus age from patients with Alzheimer's disease, non-Alzheimer type (non-AD) dementia, and normal controls; dotted line represents the cut-off level of p97 (10 pg/ $\mu \mathrm{l})$.

non-AD dementia and normal controls, but no difference between non-AD dementia and normal controls. A scatter plot of $\mathrm{p} 97$ versus age from patients and normal controls is shown in Figure 2. The p97 values of the 24 normal subjects over age 50 did not differ from those of the 60 younger normal subjects $(3.15 \mathrm{pg} / \mu \mathrm{l}, 2.03-5.63$ $\mathrm{pg} / \mu \mathrm{l}$ vs. $3.25 \mathrm{pg} / \mu \mathrm{l}, 2.90-3.80 \mathrm{pg} / \mu \mathrm{l}, p=.66$ by Kruskal-Wallis test). Because of the age difference between the normal subjects and the two clinical groups and no difference of age between the two clinical groups, we conducted a further analysis in which only the 24 normal subjects above age 50, the lowest age of any patient, were included. These 24 elderly controls had a median age of 65.5 years (interquartile range 62 68 ), somewhat below the corresponding age of the $\mathrm{AD}$ group (median 70 years, interquartile range 62-75) $(p<$ .04). Nevertheless, the significant group contrasts were the same as in the analysis without age restriction. No significant correlation was found between serum $\mathrm{p} 97$ concentration and age ( $p>.3$ for each group). There was no significant sex difference of serum p97 concentration in any group.

\section{Serum p97 and Staging of AD}

Age-adjusted comparisons of serum p97 concentrations in 38 mild $\mathrm{AD}$ subjects $(\mathrm{CDR}=0.5$ or 1.0 ; median 14.45 $\mathrm{pg} / \mu \mathrm{l}$, interquartile range $10.20-17.00 \mathrm{pg} / \mu \mathrm{l}), 33$ late AD subjects (CDR $=2.0$ or 3.0 ; median $15.00 \mathrm{pg} / \mu \mathrm{l}$, interquartile range $12.05-17.50 \mathrm{pg} / \mu \mathrm{l})$, and 140 non-AD subjects (patient controls and normal controls; $3.15 \mathrm{pg} /$ $\mu \mathrm{l}$, interquartile range $2.10-4.50 \mathrm{pg} / \mu \mathrm{l}$ ) showed that serum p97 concentration was elevated in mild $\operatorname{AD}(p=$ .0001 by analysis of covariance using ranks adjusting for age), but not further elevated in late AD.

There was a significant negative correlation between serum p97 concentration and severity of dementia by K-MMSE score in the total group of 127 demented subjects $(\rho=-0.22, p=.025)$, but not within each subgroup $(\rho=-0.19, p=.14$ for $\mathrm{AD}, \rho=-0.16, p=.36$ for non-AD dementia). Duration of illness was not correlated significantly with serum $\mathrm{p} 97$ in $\mathrm{AD}(\rho=.05, p=$ .70 by Spearman rank correlation method). There was no significant difference of serum p97 among the four different groups of AD based on CDR staging ( $p=.65$, using the Kruskal-Wallis test).

\section{Diagnostic Performance of Serum p97 as a Marker of AD}

The sensitivity, specificity, and diagnostic accuracy associated with each cut-off concentration of serum p97 were computed, and from these results ROC curves were derived. By age-adjusted analysis in the total sam- 


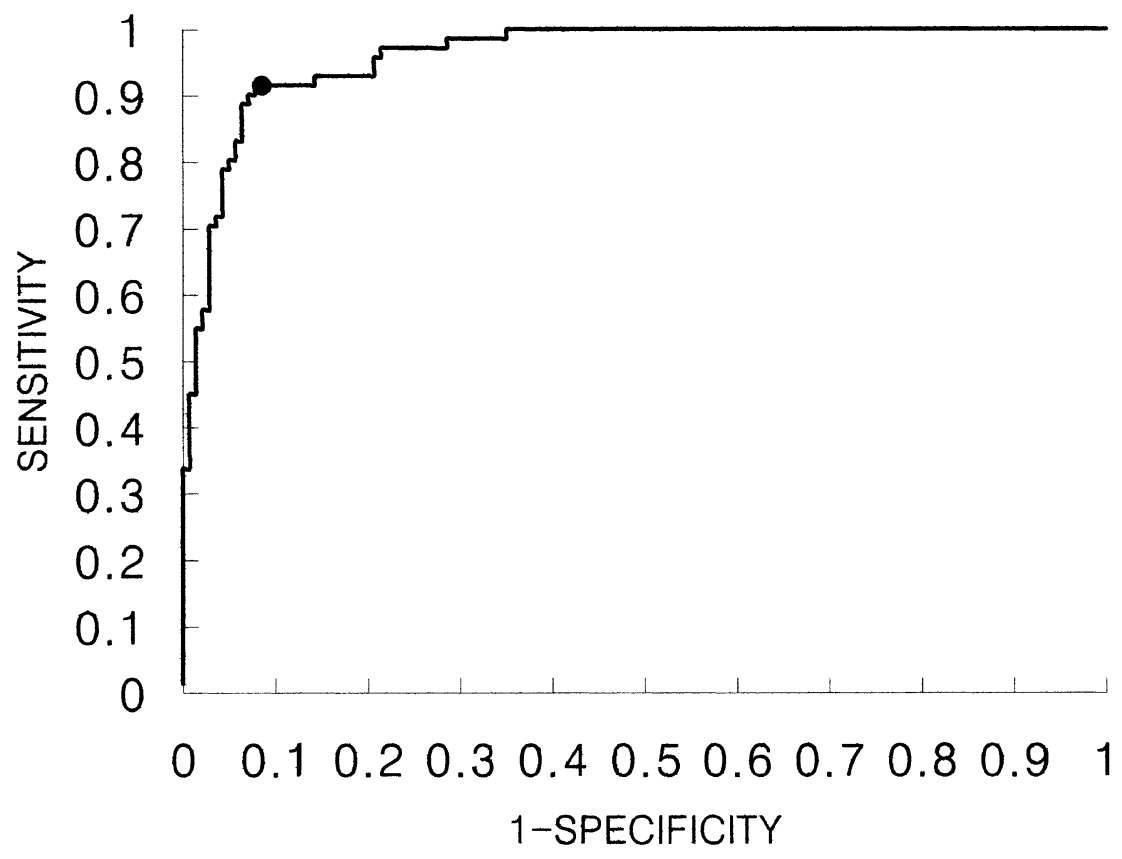

Figure 3. Receiver operating characteristic curve for the diagnosis of Alzheimer's disease by age-adjusted serum p97 concentration. The optimum serum $\mathrm{p} 97$ concentration of $10 \mathrm{pg} / \mu \mathrm{l}$ is indicated for the comparison of 71 patients with AD from 56 patients with non-AD dementia plus 84 normal control subjects. ple, the optimal ROC solution was found with a serum p97 concentration higher than or equal to $10.0 \mathrm{pg} / \mu \mathrm{l}$ (Figure 3). With this cut-off value, sensitivity, specificity, and accuracy for the diagnosis of AD from all other subjects were $0.915,0.914$, and 0.915 , respectively. In the subanalyses involving only subjects over age 50 , age adjustment was not required, and the optimal ROC solution was identical at a serum p97 concentration of $10.0 \mathrm{pg} / \mu \mathrm{l}$. The sensitivity, specificity, and accuracy of this threshold in distinguishing the 71 subjects with AD from the 80 other subjects over age 50 (24 normal controls and 56 patients with non-AD dementia) were $0.901,0.888$, and 0.894, respectively. Likewise, for the distinction simply between AD and non-AD dementia, the optimal serum p97 concentration without adjustment for age also was identical at $10.0 \mathrm{pg} / \mu \mathrm{l}$, with sensitivity, specificity, and accuracy of $0.901,0.857$, and 0.882 , respectively. Finally, to distinguish patients with $\mathrm{AD}$ from the normal control subjects over age 50, the optimal serum p97 concentration without adjustment for age was $9.0 \mathrm{pg} / \mu \mathrm{l}$, at which sensitivity, specificity, and accuracy were $0.915,0.917$, and 0.916 , respectively.

\section{Serum p97 and ApoE Genotyping}

Allelic frequencies of ApoE $\epsilon 4$ differed significantly between the $71 \mathrm{AD}$ subjects and the 140 non-AD subjects (31 and 9\%, respectively; $p(<.001)$. Serum p97 concentrations did not differ among the ApoE genotypes or in the presence of the $\epsilon 4$ allele $(p>.1)$.

\section{DISCUSSION}

Our findings confirm and modify the initial report of Kennard et al. (1996). Based on a larger sample (71 patients with the clinical diagnosis of AD, 56 demented patients with non-AD dementia diagnoses, and 84 normal subjects) we can more confidently conclude and confirm that elevated serum p97 concentrations are strongly associated with the diagnosis of AD. At a diagnostic threshold of $10 \mathrm{pg} / \mu \mathrm{l}$, both with and without adjustment for age, we obtained sensitivity estimates of 0.90 to 0.92 and specificity estimates of 0.86 to 0.91 . These results fulfill the criteria proposed by the Working Group on Molecular and Biochemical Markers of Alzheimer's Disease (The Ronald and Nancy Reagan Research Institute of the Alzheimer's Association and the National Institute on Aging Work Group 1998). The age distribution of the control group differed from that of the $\mathrm{AD}$ group, but no significant correlation between serum p97 concentration and age was detected within any group, implying that age differences among the three groups have no influence on the result. In separate analyses using only normal control subjects aged 50 years or greater, the serum p 97 concentrations of the three groups remained significantly different, again with the values significantly elevated only in AD. In this elderly sample, ROC analyses revealed an identical diagnostic threshold of $10 \mathrm{pg} / \mu \mathrm{l}$ serum p97 concentration to distinguish AD from all other subjects or just from non-AD dementia, with only minor loss of diag- 
nostic performance in the latter contrast (specificity $0.86)$.

Our results differ in some respects from the initial limited report of Kennard et al (1996). With our larger sample, we could not confirm the absence of overlap between normal and $\mathrm{AD}$ distributions of serum $\mathrm{p} 97$ concentrations. In our data, the mean $\mathrm{AD} /$ control ratio of serum p97 concentrations was 3.8 as compared with 6.2 in the data of Kennard et al. There also was a difference between the two studies with respect to the mean serum p97 concentration of control subjects: $7.04 \mathrm{pg} / \mu \mathrm{l}$ in the study of Kennard et al. who used a sandwich fluorescence immunoassay, as compared with $3.58 \mathrm{pg} /$ $\mu l$ by the immunoblot assay used in the present study. Pending research confirmation of our findings, further work will be needed to standardize the assay for serum p97 across laboratories before clinical application is considered.

In a crucial validating comparison, we found that the serum p97 concentration not only distinguished patients with $\mathrm{AD}$ from normal control subjects, but also from patients with other forms of dementia, with only slight apparent loss of diagnostic performance. Kennard et al. (1996) did not report data comparing AD with other forms of dementia. They did report nonelevated serum p97 concentrations in a very small group of five patients with nondementing neurologic disorders. We have now extended the clinical specificity of the serum p97 concentration to include vascular dementia $(n=41)$ and dementia associated with Parkinson's disease $(n=15)$.

We found elevation of the serum p97 concentration even in mild $\mathrm{AD}(\mathrm{CDR}=0.5$ or 1.0$)$, which suggests that the serum p97 concentration may be useful in the differential diagnosis of AD from other dementias early in the illness, when clinical uncertainty is greatest. Previous reports indicate that the neurofibrillary lesions and amyloid plaques that are diagnostic of $\mathrm{AD}$ and that are associated with elevated p97 concentrations in brain tissue (Jefferies et al. 1996a) commence in the medial temporal lobe long before clinical symptoms appear (Nagy et al. 1999; Delacourte et al. 1999). This finding makes elevation of serum p97 concentration early in the clinical course of $\mathrm{AD}$ more understandable. It remains to be seen whether elevated serum p97 concentrations will identify presymptomatic individuals who will later develop clinical AD.

At the same time, the absence of further elevation of serum p97 concentration in late $\mathrm{AD}(\mathrm{CDR}=2.0$ or 3.0$)$ and the lack of significant correlations with duration of symptoms or severity of dementia in AD suggest that the serum p97 concentration would not be a useful marker of the progression of AD. In this respect, our data differ from those of Kennard et al. (1996), who did report a significant correlation of serum p97 concentration with duration of clinical symptoms. Whether the serum p97 concentration might be useful in evaluating the effects of treatment in AD is unknown.

The lack of complete agreement between clinical diagnosis and classification by serum p97 concentration may reflect true nonspecificity and incomplete sensitivity of the laboratory measure, or it could rather reflect error in the clinical diagnoses. Mathematical modeling (Carroll 1989) reveals that a laboratory measure that actually has $100 \%$ sensitivity, and $100 \%$ specificity will seem to be $85 \%$ sensitive and $85 \%$ specific when Cohen's kappa coefficient of agreement between the clinical diagnoses and the "gold standard" pathologic diagnoses is 0.7. At that level of diagnostic accuracy and assuming symmetrical errors, the over-all agreement of clinical and pathologic diagnoses will be $85 \%$, a figure commonly cited in AD research units. In particular, the specificity of standard clinical criteria for AD may be quite low for such contrasts such as frontotemporal dementia (Varma et al. 1999; Klatka et al. 1996).

It is known that p97 co-localizes with the transferrin receptor in brain capillary endothelium, which suggests that the soluble p97 protein could cross the blood-brain barrier by interacting with the transferrin receptor (Rothenberger et al. 1996). p97 provides a novel route for cellular uptake of iron from Fe-citrate that does not require transferrin (Jefferies et al. 1996b). Kennard and colleagues reported that the concentration of the soluble form of p97 in cerebrospinal fluid is two to four times that in serum (Kennard et al. 1996). Hence, elevation of p97 in the brain may result in the elevation of serum p97 concentration through the CSF route. Because p97 is localized to microglial cells associated with amyloid plaques in $\mathrm{AD}$, an elevated serum p97 concentration would have to be regarded as a surrogate marker (Feinstein 1977) of AD. It clearly would not be a candidate etiopathologic marker of AD.

Additional studies will be needed to validate these promising findings. Priority follow-up studies now indicated are: (1) an expanded sample of elderly normal subjects; (2) patients with such other prevalent causes of dementia as alcohol-related dementia, frontotemporal dementia, and dementia with Lewy bodies; (3) independent samples of the clinical groups we studied (AD, vascular dementia, and Parkinson's disease with dementia); (4) autopsy checking of the premortem diagnostic performance of the serum p97 concentration; (5) longitudinal studies of incident dementia; and (6) documentation of serum p97 concentrations in other disorders of iron transport and metabolism.

\section{REFERENCES}

Carroll BJ (1989): Diagnostic validity and laboratory studies: Rules of the game. In Robins LN, Barrett JE (eds), The 
Validity of Psychiatric Diagnosis. New York, Raven Press, pp 229-245

Delacourte A, David JP, Sergeant N, Buee L, Wattez A, Vermersch P, Ghozali F, Fallet-Bianco C, Pasquier F, Lebert F, Petit H, Di Menza C (1999): The biochemical pathway of neurofibrillary degeneration in aging and Alzheimer's disease. Neurology 52:1158-1165

Feinstein AR (1977): On the Sensitivity, Specificity, and Discrimination of Diagnostic Tests. Clinical Biostatistics. St. Louis, MO, C. V. Mosby

Folstein MF, Folstein SE, McHugh PR (1975): “Mini-mental state" a practical method for grading the cognitive state of patients for the clinician. J Psychiat Res 12:189-198

Geldmacher DS, Whitehouse PJ (1996): Evaluation of dementia. N Engl J Med 335:330-336

Hixson JE, Vernier DT (1990): Restriction isotyping of human apolipoprotein $\mathrm{E}$ by gene amplification and cleavage with Hha I. J Lipid Res 31:545-548

Hughes AJ, Daniel SE, Kilford L, Lees AJ (1992): Accuracy of clinical diagnosis of idiopathic Parkinson's disease: A clinco-pathological study of 100 cases. J Neurol Neurosurg Psychiat 55:181-184

Jefferies WA, Food MR, Gabathuler R, Rothenberger S, Yamada T, Yasuhara O, McGeer PL (1996a): Reactive microglia specifically associated with amyloid plaques in Alzheimer's disease brain tissue express melanotransferrin. Brain Res 712:122-126

Jefferies WA, Gabathuler R, Kennard ML (1996b): Pumping iron in the '90s. Trends Cell Biol 6:223-228

Kennard ML, Richardson DR, Gabathuler R, Ponka P, Jefferies WA (1995): A novel iron uptake mechanism mediated by GPI-anchored human p97. EMBO J 14:41784186

Kennard ML, Feldman H, Yamada T, Jefferies WA (1996): Serum levels of iron binding protein p97 are elevated in Alzheimer's disease. Nature Med 2:1230-1235

Klatka LA, Schiffer RB, Powers JM, Kazee AM (1996): Incorrect diagnosis of Alzheimer's disease, a clinicopathological study. Arch Neurol 53:35-42
McKhann G, Drachman D, Folstein M, Katzman R, Price D, Stadlan EM (1984): Clinical diagnosis of Alzheimer's disease: Report of the NINCDS-ADRDA work group under the auspices of Alzheimer's disease. Neurology 34:939-944

Morris JC (1993): The clinical dementia rating (CDR): Current version and scoring rules. Neurology 43:2412-2414

Nagy Z, Hindley NJ, Braak H, Braak E, Yilmazer-Hanke DM, Schultz C, Barnetson L, Jobst KA, Smith AD (1999): Relationship between clinical and radiological diagnostic criteria for Alzheimer's disease and the extent of neuropathology as reflected by stages: a prospective study. Dement Geriatr Cogn Disord 10:109-114

Roman GC, Tatemichi TK, Erkinjuntti T, Cummings JL, Masdeu JC, Garcia JH, Amaducci L, Orgogozo JM, Brun A, Hofman A, Moody DM, O'Brien MD, Yamaguchi T, Grafman J, Drayer BP, Bennett DA, Fisher M, Ogata J, Kokmen E, Bermejo F, Wolf PA, Gorelick PB, Bick KL, Pajeau AK, Bell MA, DeCarli C, Culebras A, Korczyn AD, Bogousslavsky J, Hartmann A, Scheinberg P (1993): Vascular dementia: Diagnostic criteria for research studies. Report of the NINDS-AIREN International Workshop. Neurology 43:250-260

Rothenberger S, Food MR, Gabathuler R, Kennard ML, Yamada T, Yasuhara O, McGeer PL, Jefferies WA (1996): Coincident expression and distribution of melanotransferrin and transferrin receptor in human capillary endothelium. Brain Res 712:117-121

Streiner DL, Norman GR (1995): Health Measurement Scales, 2nd ed. New York, Oxford University Press, pp 96-100

The Ronald and Nancy Reagan Research Institute of the Alzheimer's Association and the National Institute on Aging Working Group (1998): Consensus report of the working group on molecular and biochemical markers of Alzheimer's disease. Neurobiol Aging 19:109-116

Varma AR, Snowden JS, Lloyd JJ, Talbot PR, Mann DM, Neary D (1999): Evaluation of the NINCDS-ADRDA criteria in the differentiation of Alzheimer's disease and frontotemporal dementia. J Neurol Neurosurg Psychiat 66:184-188 